\section{Case Report}

Korean J Transplant 2020;34:210-216

https://doi.org/10.4285/kjt.2020.34.3.210
Received June 16, 2020

Revised July 16, 2020

Accepted July 16, 2020

Corresponding author: Shin Hwang Department of Surgery, Asan Medical Center, University of Ulsan College of Medicine, 88 Olympic-ro 43-gil, Songpagu, Seoul 05505, Korea

Tel: +82-2-3010-3930

Fax: +82-2-3010-6701

E-mail: shwang@amc.seoul.kr

(C) The Korean Society for Transplantation This is an Open Access article distributed under the terms of the Creative Commons Attribution Non-Commercial License (http://creativecommons.org/licenses/ by-nc/4.0/) which permits unrestricted non-commercial use, distribution, and reproduction in any medium, provided the original work is properly cited.

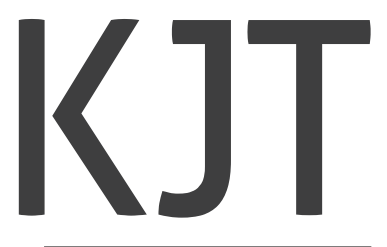

pISSN 2671-8790

elSSN 2671-8804

\title{
Graft outflow vein venoplasty for a laparoscopically harvested left lateral section graft in pediatric living donor liver transplantation
}

\author{
Jung-Man Namgoong ${ }^{1}$, Shin Hwang ${ }^{1}$, Ki-Hum Kim ${ }^{1}$, Gil-Chun Park ${ }^{1}$, Kyung Mo Kim², \\ Seak Hee $\mathrm{Oh}^{2}$, Hyunhee Kwon ${ }^{1}$, Yong Jae Kwon ${ }^{1}$ \\ 1Department of Surgery, Asan Medical Center, University of Ulsan College of Medicine, Seoul, Korea \\ ${ }^{2}$ Department of Pediatrics, Asan Medical Center, University of Ulsan College of Medicine, Seoul, Korea
}

Laparoscopically harvested left lateral section (LLS) grafts have drawbacks regarding the size of the graft left hepatic vein (LHV) orifice although they have the merit of cosmetics concerning the donor's wound. We present a case of pediatric living donor liver transplantation (LDLT) using a laparoscopically harvested LLS graft and describe the refined surgical techniques for graft LHV venoplasty with a circumferential vein patch. The patient was a 46-month-old boy with marked growth retardation who was diagnosed with progressive familial intrahepatic cholestasis type 2. The donor was his 25-yearold mother. The LLS graft weighed $285 \mathrm{~g}$. A circumferential patch of external iliac vein homograft was attached to the graft LHV orifice after incisions were made at the medial wall of the LHV trunk and superficial LHV branch, which made the graft LHV orifice much larger. The recipient's hepatic vein orifice was also enlarged by unifying the three hepatic vein orifices. Other surgical procedures followed the standard LDLT operation. This patient recovered uneventfully and has been doing well for 1 year. In conclusion, our incision-and-patch venoplasty to enlarge the graft outflow vein orifice was beneficial for reducing the risk of hepatic vein outflow obstruction in LDLT using a laparoscopically harvested LLS graft.

Keywords: Left hepatic vein; Venoplasty; Vein patch, Stenosis; Pediatric transplantation

\section{INTRODUCTION}

Living donor hepatectomy by total laparoscopy has definite merit for the cosmetic aspect of the donor's abdominal wound [1-5]. In contrast, it also has drawbacks in the liver graft per se, especially for the graft hepatic vein, which is transected by an endoscopic vascular stapler and excision of the stapled hepatic vein portion at the graft. This procedure significantly shortens the graft hepatic vein stump, which is often unsuitable for direct anastomosis.

In pediatric living donor liver transplantation (LDLT) using a left lateral section (LLS) graft, the left hepatic vein (LHV) is usually small, as is the LLS graft. Laparoscopic donor hepatectomy results in a smaller and shorter graft LHV orifice than that with conventional open donor surgery; thus, venoplasty is often necessary to enlarge the hepatic vein orifice to minimize the risk of hepatic vein outflow obstruction. Because some degree of anasto- 


\section{HIGHLIGHTS}

- An incision-and-patch venoplasty to enlarge the graft outflow vein orifice is beneficial for reducing the risk of hepatic vein outflow obstruction in living donor liver transplantation using left lateral section graft that is harvested laparoscopically.

motic stenosis inevitably develops at the site of graft LHV reconstruction in pediatric LDLT [6], it is important to make both the graft and the recipient's hepatic vein orifices large enough to compensate for such surgical procedure-related stenosis. We herein present a case of pediatric LDLT using a laparoscopically harvested LLS graft and describe the refined surgical techniques for graft LHV venoplasty with a circumferential vein patch.

\section{CASE REPORT}

The pediatric patient was a 46-month-old boy, $89 \mathrm{~cm}$ in height and $12 \mathrm{~kg}$ in weight, who was diagnosed with progressive familial intrahepatic cholestasis type 2 . When he was 6 months old, jaundice and hepatomegaly started and progressed with no response to medication. He showed growth retardation, in which his height and weight were below the third percentile. As his general condition deteriorated progressively (Fig. 1), we decided to perform LDLT.

The donor was his 25-year-old mother. Computed tomography volumetry showed estimated volumes of the left hemiliver and LLS of $365 \mathrm{~mL}$ and $300 \mathrm{~mL}$, respectively (Fig. 2). The total fatty change was less than $5 \%$ on mag- netic resonance spectrometry. Total laparoscopic hepatectomy for an LLS graft harvest was performed. The graft LHV trunk was transected with a bilateral endovascular stapler under gentle traction of the LLS graft. The isolated liver graft was delivered through a small suprapubic incision. Just after delivery of the LLS graft to the back table, the stapled LHV orifice at the graft side was excised for drainage of the perfusate solution. The donor recovered uneventfully from the donor surgery.

The LLS graft weighed $285 \mathrm{~g}$, corresponding to a graft-recipient weight ratio of $2.4 \%$. The transverse diameter of the graft LHV orifice was only $17 \mathrm{~mm}$ (Fig. 3A), which was smaller than the estimated hepatic vein orifice at the recipient's inferior vena cava (IVC). To enlarge the LHV orifice, we made a $1-\mathrm{cm}$-long incision at the medial wall of the LHV trunk (Fig. 3B) and attached a cryopreserved external iliac vein homograft patch to the wall defect (Fig. 3C). Thereafter, we incidentally found a superficial LHV branch at the lateral side of the LHV orifice. The overlying wall of this small vein was opened by $5 \mathrm{~mm}$ (Fig. 3D) and the defect was covered with a small piece of the vein homograft (Fig. 3E). Finally, we attached a circumferential vein patch at the graft LHV orifice, thus enlarging the transverse diameter to $35 \mathrm{~mm}$ (Fig. 3F).

After completing the dissection of the recipient's native liver, we transected the right and left hepatic arteries at the highest level because the graft left hepatic artery had a very short stump (Fig. 4A). We transected the portal vein at the level of the second-order branch for using it as a branch patch after marking the axis of the portal vein with a surgical marking pen (Fig. 4B). After total clamping of the IVC, we incised the hepatic parenchyma with a surgical knife, leaving the bulk of the hepatic parenchyma around the hepatic vein trunks. Next, we made a longitudinal incision at the hepatic parenchyma between the right and
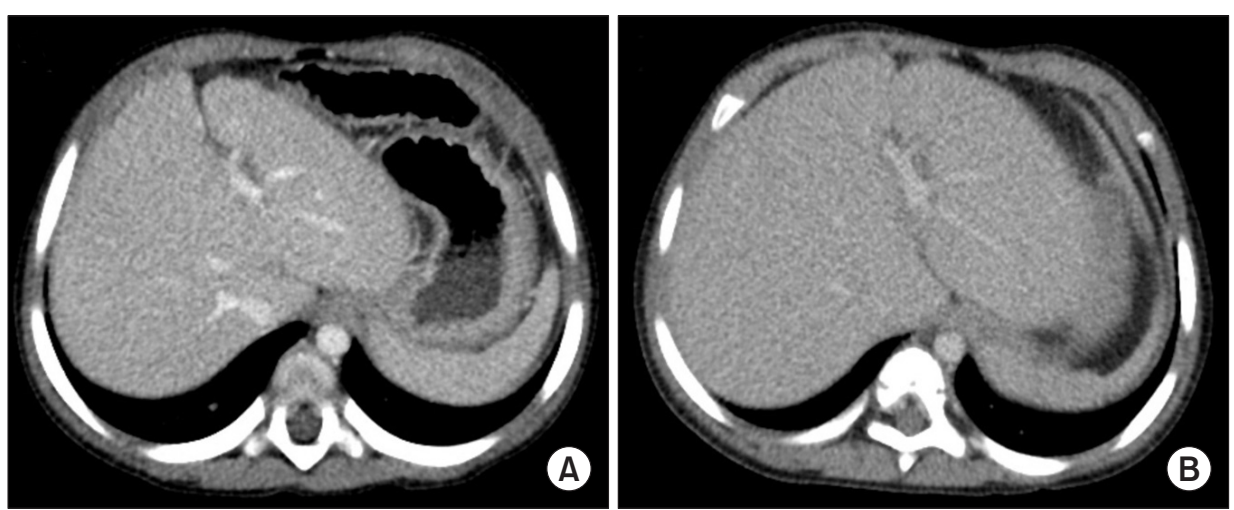

Fig. 1. Pretransplant computed tomography (CT) scans. Progression of hepatomegaly is shown between CT scans taken at 6 months (A) and 1 month (B) before transplantation. 

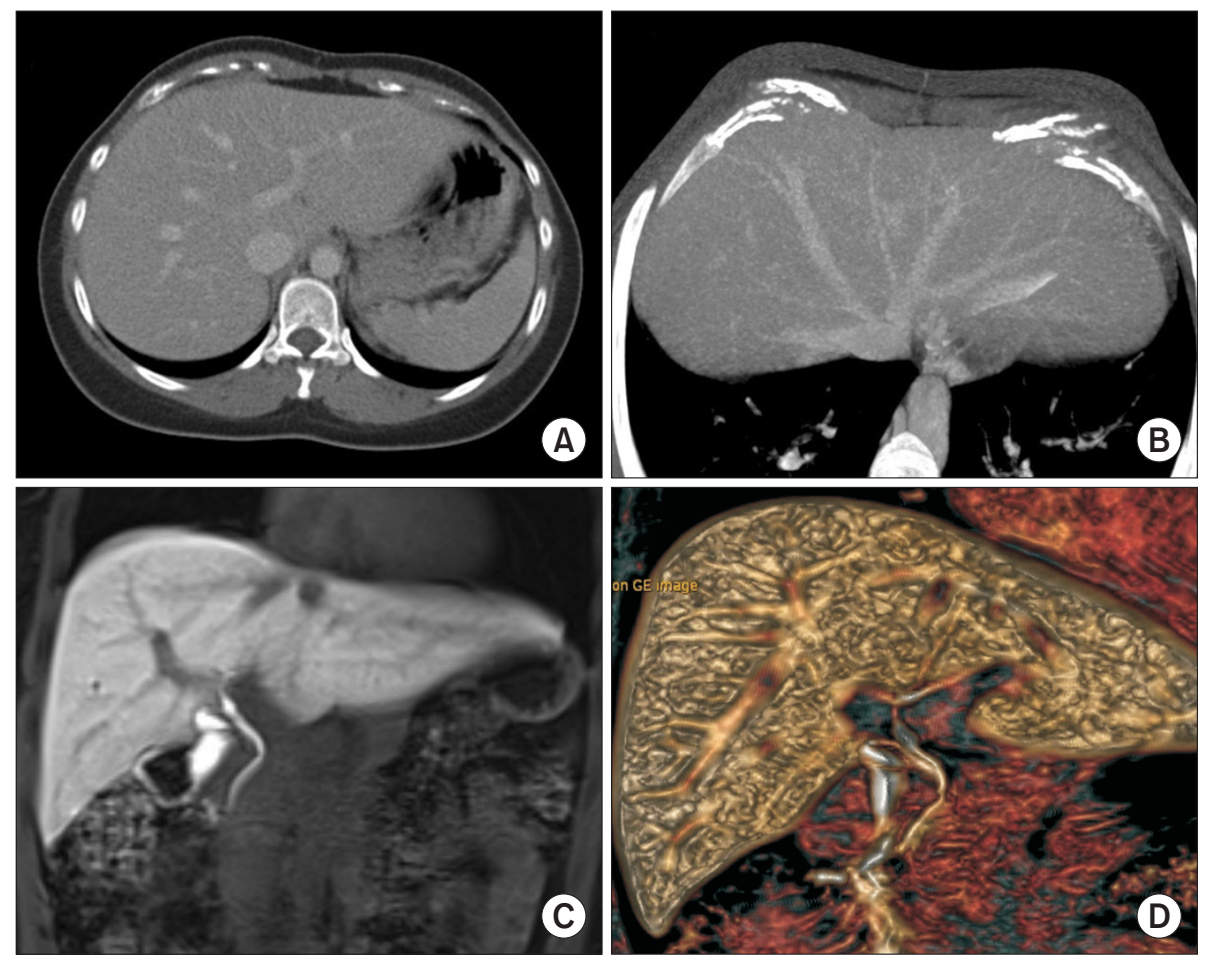

Fig. 2. Preoperative imaging studies of the living donor. Computed tomography scan images showing the volume of the left lateral section $(A)$ and the anatomy of the left hepatic vein (B). Magnetic resonance imaging study showing the vascular (C) and biliary (D) anatomy.
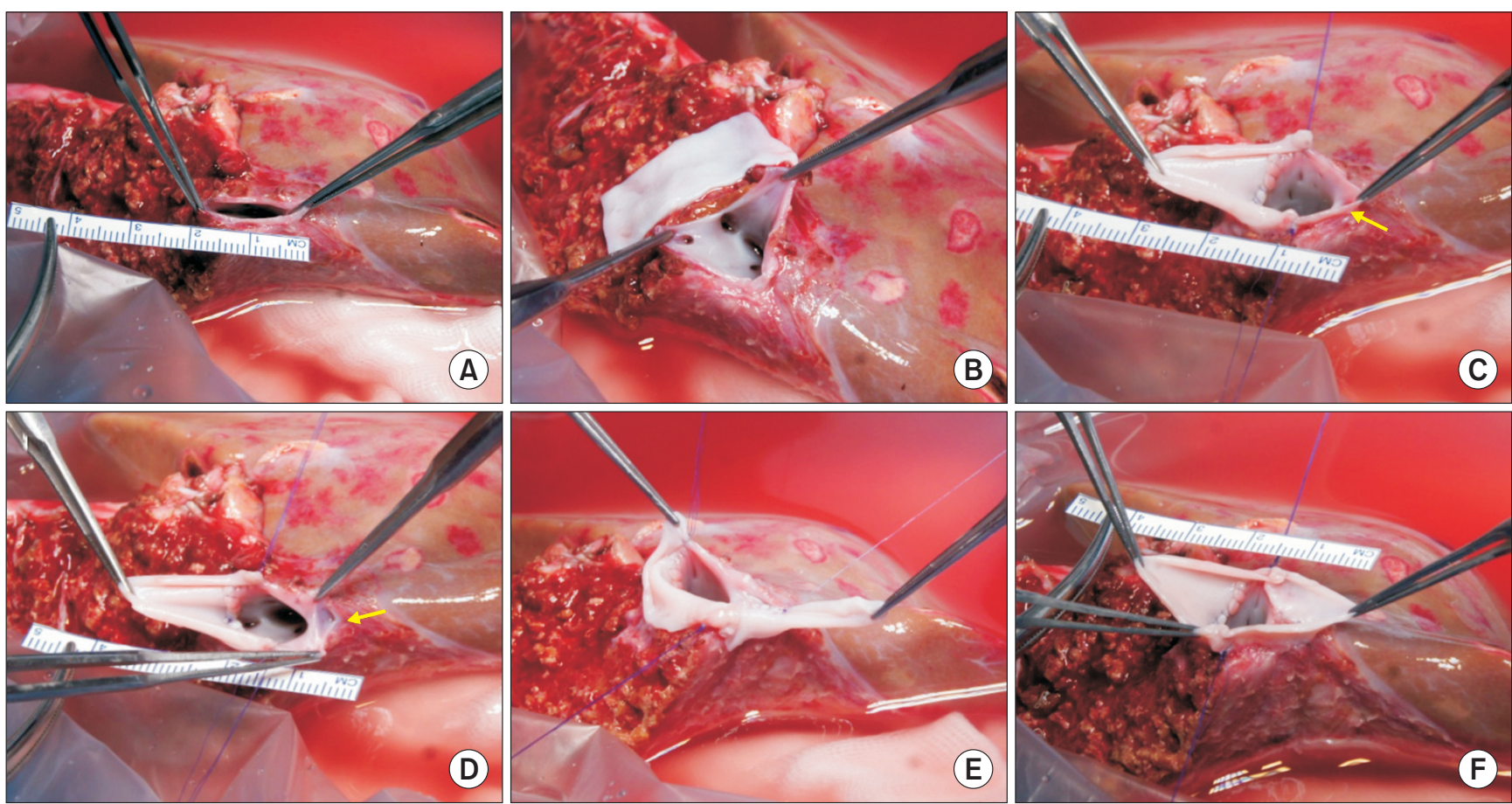

Fig. 3. Intraoperative photographs of the graft hepatic vein venoplasty at the back table. (A) The transverse diameter of the graft left hepatic vein (LHV) orifice was only $17 \mathrm{~mm}$. (B) We made a $10 \mathrm{~mm}$-long incision at the medial wall of the LHV trunk to enlarge the orifice. (C) A cryopreserved external iliac vein homograft patch was attached to the wall defect. Thereafter, we found a superficial LHV branch at the lateral side of the LHV orifice (arrow). (D, E) The overlying wall of this small vein was opened by $5 \mathrm{~mm}$ and the defect was covered with a small piece of the vein homograft. (F) A circumferential vein patch was finally attached at the graft LHV orifice and its transverse diameter was enlarged to $35 \mathrm{~mm}$. 

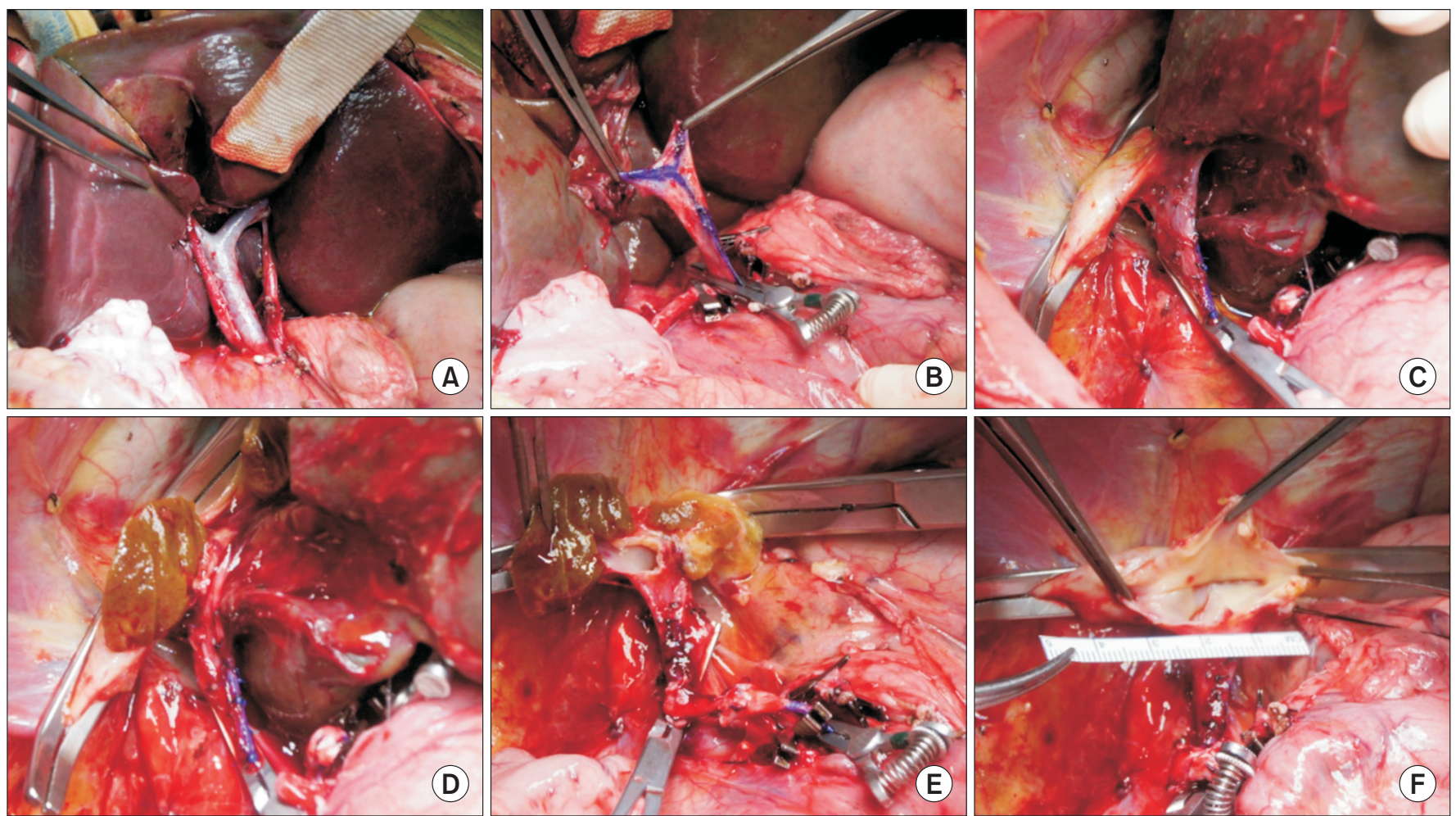

Fig. 4. Intraoperative photographs of the recipient hepatectomy. (A, B) We transected the right and left hepatic arteries at the highest level and transected the portal vein at the level of the second-order branch after marking the axis of the portal vein. (C, D) After total clamping of the inferior vena cava, we incised the hepatic parenchyma using a surgical knife, leaving the bulk of the hepatic parenchyma around the hepatic vein trunk. (E) The attached hepatic parenchyma was forcefully pulled out to detach it from the hepatic vein stumps. $(F)$ The septa between the right and middle hepatic veins and the middle and left hepatic veins were incised to make a single large hepatic vein orifice with a $38 \mathrm{~mm}$-wide transverse diameter.

middle hepatic vein trunks and, then, separated the attached hepatic parenchyma into two parts (Fig. 4C and D). Thereafter, the hepatic parenchyma was forcefully pulled out to detach it from the hepatic vein stumps, which made the hepatic vein stump walls long and thick (Fig. 4E). At this time, we incised the IVC wall septa between the right and middle hepatic veins and the middle and LHVs consecutively to make a single large hepatic vein orifice. The transverse diameter of this unified hepatic vein orifice was $38 \mathrm{~mm}$ (Fig. 4F), although the diameter of the retrohepatic IVC was less than $20 \mathrm{~mm}$.

At the start of graft implantation, we tagged the right and left corners of the graft and the recipient's hepatic vein orifices with 5-0 polydioxanone (PDS) to match their sizes. Then, continuous sutures of the posterior wall continued first from the left corner to the 6 o'clock direction (Fig. 5A and B) and continued toward the right corner after meticulous size patching (Fig. 4D). After placing a fixation suture at the right corner, the continuous running suturing continued to anastomose the anterior wall (Fig. 5A and B). After injecting heparinized saline into the IVC lumen, we completed the graft hepatic vein reconstruction.

Thereafter, we stretched the branch patch of the recipient's portal vein toward the graft portal vein and performed continuous suturing with a 6-0 PDS for portal vein reconstruction (Fig. $5 \mathrm{C}$ and $\mathrm{D}$ ) and began graft reperfusion (Fig. 5E). We reconstructed the graft left hepatic artery using the recipient's left hepatic artery branch under surgical microscopy (Fig. 5F). We performed hepaticojejunostomy using a Roux-en-Y jejunal limb. This patient recovered uneventfully without any surgical complication (Fig. 6) and has been doing well for 1 year to date.

\section{DISCUSSION}

Pediatric LDLT in small-sized recipients is vulnerable to 

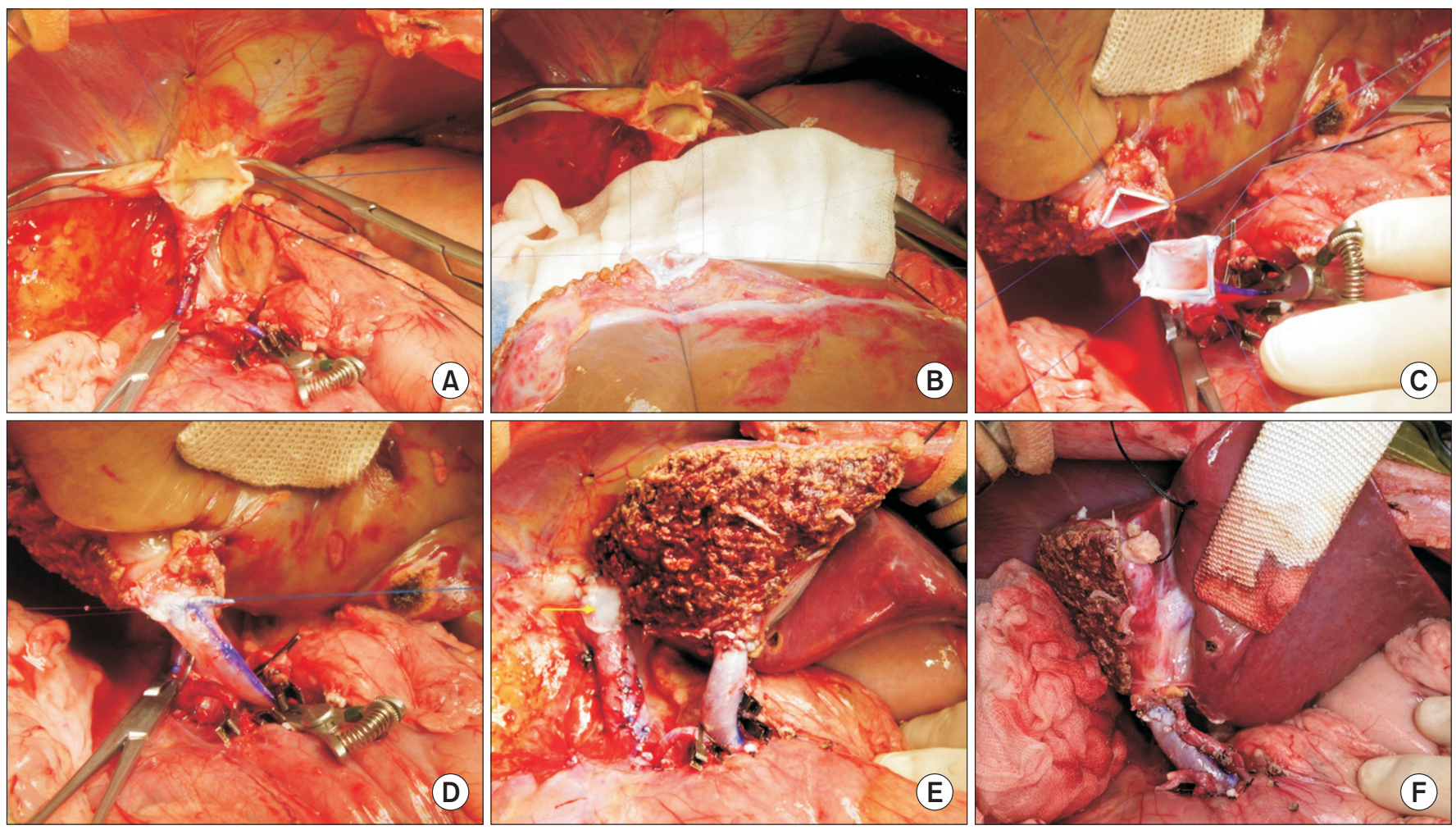

Fig. 5. Intraoperative photographs of the graft implantation. $(A, B)$ The right and left corners of the graft and recipient's hepatic vein orifices were tagged with 5-0 polydioxanone (PDS) and anastomosed with continuous sutures at the posterior and anterior walls. (C, D) The portal vein was reconstructed with the branch patch of the recipient's portal vein stump using a 6-0 PDS. (E) A vein homograft patch attached at the graft hepatic vein (arrow) made the graft hepatic vein anastomosis definitely wide. (F) The graft left hepatic artery was reconstructed under surgical microscopy using the recipient's left hepatic artery branch.

various vascular complications because the graft and recipient vessels are small, and the posttransplant use of endovascular stenting cannot be a definitive treatment in those cases. For hepatic vein reconstruction in LDLT using an LLS graft, anastomotic stenosis is usually attributed to the small size of the anastomosis per se. Once anastomotic stenosis of the graft hepatic vein develops, it is not easily treated by percutaneous radiological angioplasty as the connective tissues around the vascular structures are hardened; thus, repeated intervention is often needed [711]. Hence, an evidence-based secure surgical design is essential for outflow hepatic vein reconstruction in pediatric LDLT.

Compared to the usual LLS grafts harvested through an open surgery, those harvested through a laparoscopic approach have some drawbacks. First, the stump of the graft LHV orifice is much shorter. Second, the stump of the graft left hepatic artery is also shorter. And third, the hepatic duct opening becomes smaller because the transection line at the left hepatic duct moves toward the left liver side. There may be no difference in the left portal vein stump as the left portal vein is long enough for safe transection. To address these drawbacks of laparoscopically harvested LLS grafts, we have paid special attention towards making the graft hepatic vein as large as possible and transecting the recipient's hepatic artery as long as possible. Through these efforts, we feel that the posttransplant outcomes of pediatric LDLT are quite comparable between open and laparoscopically harvested LLS grafts [1-4].

To enlarge the hepatic vein orifice in an LLS graft, we have used an incision-and-patch venoplasty technique for a long period, in which we incised the medial side of the LHV wall and attached a homograft vein patch to cover the defect. Additionally, it is important to note that a small superficial branch of the LHV, if present, was incised, and a vein patch was applied to facilitate the enlargement of the graft hepatic vein orifice. For laparoscopically harvested LLS grafts, we made a small incision at the medial 

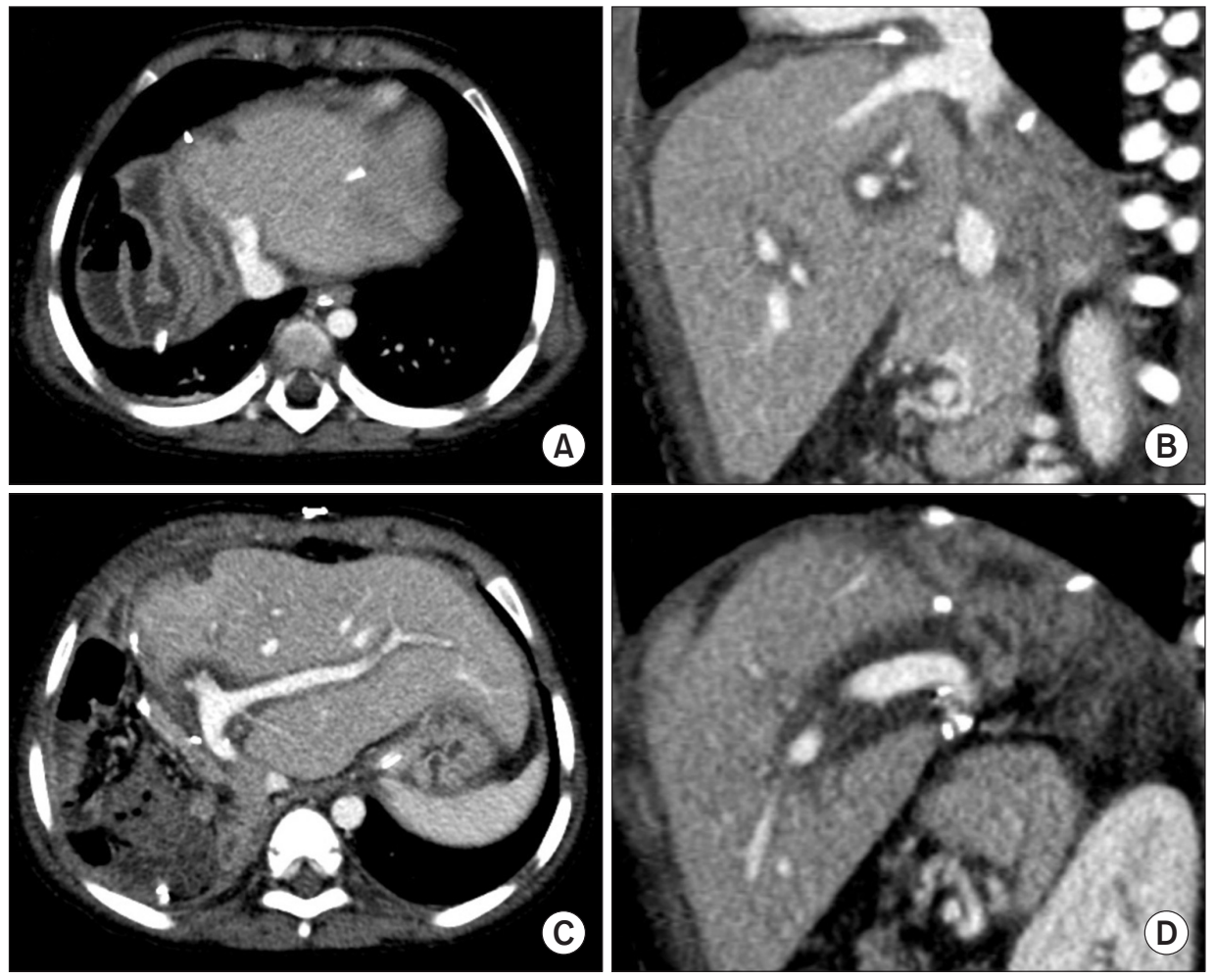

Fig. 6. Posttransplant computed tomography scans taken 5 days after transplantation showing smooth-streamlined reconstruction of the hepatic $(A, B)$ and portal $(C, D)$ veins.

wall of the LHV orifice in the absence of a superficial LHV branch or at this branch if it was present and attached a circumferential vein patch because the graft LHV stump was usually too short for direct anastomosis. In the present case, we made a medial-side incision first, not having recognized the presence of a superficial LHV branch as it was very small. After recognizing this small vein, we also used it for patch venoplasty to further enlarge the graft hepatic-vein orifice.

The superficial branch of the LHV is usually too small to identify in preoperative donor computed tomography or magnetic resonance imaging studies; thus, a unification venoplasty using this vein branch has to be decided after careful examination of the LLS graft at the back table. The clinical importance of this small vein branch has yet not been evaluated, primarily because its drainage territory is negligibly small $[12,13]$. Based on our experience, any small superficial branch of the LHV can be effectively used for unification venoplasty.

The cryopreserved external iliac vein homograft used in this case was obtained from the institutional tissue bank of our institution. All human tissues stored at the tissue bank were donated after receiving informed consent from the donors' family members. All procedures for vascular tissue procurement and processing complied with Korean legislation and conformed to the ethical and safety concerns for therapeutic use [14]. Currently, cryopreserved femoral vein and artery homografts are available through the Korea Public Tissue Bank. The vein homograft patch used in the present case would be accommodated as a part of graft hepatic vein; thus, some redundant portions at the hepatic vein anastomosis would be shrunken according to the principles of hemodynamics.

In conclusion, a laparoscopically harvested LLS graft has drawbacks for small graft LHV, although it is better cosmetically for the donor's wound. Therefore, an incision-and-patch venoplasty to enlarge the graft outflow vein orifice using a laparoscopically harvested LLS graft is necessary to reduce the risk of hepatic vein outflow obstruction in pediatric LDLT.

\section{ACKNOWLEDGMENTS}

\section{Conflict of Interest}

Shin Hwang is an editorial board member of the journal but did not involve in the peer reviewer selection, evalua- 
tion, or decision process of this article. No other potential conflicts of interest relevant to this article were reported.

\section{ORCID}

\section{Jung-Man Namgoong}

https://orcid.org/0000-0002-9237-7440

Shin Hwang

Ki-Hun Kim https://orcid.org/0000-0002-9045-2531

Gil-Chun Park https://orcid.org/0000-0002-4016-0995

Kyung Mo Kim https://orcid.org/0000-0003-1631-3258

Seak Hee Oh https://orcid.org/0000-0001-7896-6751

Hyunhee Kwon https://orcid.org/0000-0002-9672-8877

Yong Jae Kwon https://orcid.org/0000-0001-9490-1229

\section{Author Contributions}

Conceptualization: SH. Data curation: JMN, KMK, SHO. Methodology: KHK, CGP, HK, YJK. Visualization: SH. Writing-original draft: $\mathrm{SH}, \mathrm{JMN}$. Writing-review \& editing: $\mathrm{SH}$.

\section{REFERENCES}

1. Scatton O, Katsanos G, Boillot O, Goumard C, Bernard D, Stenard $F$, et al. Pure laparoscopic left lateral sectionectomy in living donors: from innovation to development in France. Ann Surg 2015;261:506-12.

2. Broering DC, Elsheikh Y, Shagrani M, Abaalkhail F, Troisi RI. Pure laparoscopic living donor left lateral sectionectomy in pediatric transplantation: a propensity score analysis on 220 consecutive patients. Liver Transpl 2018;24:1019-30.

3. Gautier S, Monakhov A, Gallyamov E, Tsirulnikova O, Zagaynov E, Dzhanbekov T, et al. Laparoscopic left lateral section procurement in living liver donors: a single center propensity score-matched study. Clin Transplant 2018;32:e13374.

4. Soubrane $\mathrm{O}$, de Rougemont $\mathrm{O}$, Kim KH, Samstein B, Mamode N, Boillot $\mathrm{O}$, et al. Laparoscopic living donor left lateral sectionectomy: a new standard practice for donor hepatectomy. Ann Surg 2015;262:757-63.
5. Cho JY, Han HS, Kaneko H, Wakabayashi G, Okajima H, Uemoto $S$, et al. Survey results of the expert meeting on laparoscopic living donor hepatectomy and literature review. Dig Surg 2018;35:289-93.

6. Karakayali H, Boyvat F, Coskun M, Isiklar I, Sözen H, Filik L, et al. Venous complications after orthotopic liver transplantation. Transplant Proc 2006;38:604-6.

7. Galloux A, Pace E, Franchi-Abella S, Branchereau S, Gonzales E, Pariente D. Diagnosis, treatment and outcome of hepatic venous outflow obstruction in paediatric liver transplantation: 24-year experience at a single centre. Pediatr Radiol 2018;48:667-79.

8. Katano T, Sanada Y, Hirata Y, Yamada N, Okada N, Onishi $Y$, et al. Endovascular stent placement for venous complications following pediatric liver transplantation: outcomes and indications. Pediatr Surg Int 2019;35:1185-95.

9. Zhang ZY, Jin L, Chen G, Su TH, Zhu ZJ, Sun LY, et al. Balloon dilatation for treatment of hepatic venous outflow obstruction following pediatric liver transplantation. World J Gastroenterol 2017;23:8227-34.

10. Lu KT, Cheng YF, Chen TY, Tsang LC, Ou HY, Yu CY, et al. Efficiency of transluminal angioplasty of hepatic venous outflow obstruction in pediatric liver transplantation. Transplant Proc 2018;50:2715-7.

11. Yeh YT, Chen CY, Tseng HS, Wang HK, Tsai HL, Lin NC, et al. Enlarging vascular stents after pediatric liver transplantation. J Pediatr Surg 2017;52:1934-9.

12. Imamura $H$, Makuuchi $M$, Sakamoto $Y$, Sugawara $Y$, Sano K, Nakayama A, et al. Anatomical keys and pitfalls in living donor liver transplantation. J Hepatobiliary Pancreat Surg 2000;7:380-94.

13. Matsunami $H$, Makuuchi $M$, Kawasaki S, Hashikura $Y$, Ikegami T, Nakazawa Y, et al. Venous reconstruction using three recipient hepatic veins in living related liver transplantation. Transplantation 1995;59:917-9.

14. Kwon $\mathrm{H}$, Kwon $\mathrm{H}$, Hong JP, Han Y, Park H, Song GW, et al. Use of cryopreserved cadaveric arterial allograft as a vascular conduit for peripheral arterial graft infection. Ann Surg Treat Res 2015;89:51-4. 